\title{
NGHIÊN CÚU MỘT SỐ GIẢI PHÁP CÔNG NGHỆ TRONG ĐO VẼ BẢN ĐỒ ĐỊA HİNH ĐÁY BIỂN VEN BỜ PHỤC VỤ KHẢO SÁT THIÊT KẾ CÁC CÔNG TRÌNH CẢNG BIỂN VIỆT NAM
}

\author{
TS. TRẦN VIÉT TUẤN \\ Trường Đại học Mỏ-Địa chất Hà Nội
}

\section{Tóm tắt:}

Nội dung của bài báo trình bày một số kết quả nghiên cứu về các giải pháp công nghệ được áp dụng khi đo vẽ bản đồ địa hình đáy biển ven bờ khi khảo sát thiết kế và thi công các công trình cảng biển ở Việt Nam. Một số kết quả đo đạc và tính toán thực nghiệm trong đo vẽ địa hình dưới nước.

\section{1. Đặt vấn đề}

$\mathrm{H}$ iện nay ở Việt Nam việc xây dựng mới và cải tạo nâng cấp các công trình cảng biển có ý nghĩa rất quan trọng trong sự phát triển nền kinh tế biển. Để khảo sát thiết kế và thi công xây dựng các công trình cảng biển cần phải đo vẽ bản đồ địa hình đáy biển ven bờ tỷ lệ lớn. Do đặc điểm đo vẽ địa hình dưới nước ven bờ có chế độ thủy triều phức tạp, chịu ảnh hưởng của các yếu tố ngoại cảnh như: sóng biển, gió v.v... nên công tác đo đạc thành lập bản đồ địa hình đáy biển ven bờ có nhiều điểm khác biệt so với các phương pháp đo vẽ truyền thống trên đất liền. Mặt khác, các công trình xây dựng cảng biển là địa hình tiếp giáp giữa biển và đất liền nên nhiều nơi có địa hình phức tạp không đủ điều kiện cho các tàu khảo sát hoạt động. Vì vậy, cần phải nghiên cứu các giải pháp công nghệ và thiết bị đo đạc nhằm đảm bảo độ chính xác và nâng cao hiệu quả của công tác đo vẽ bản đồ địa hình đáy biển ven bờ, phục vụ cho công tác khảo sát thiết kế và thi công xây dựng các công trình cảng biển ở nước ta.

\section{Cơ sở lý thuyết và phương pháp nghiên cứu}

2.1. Đặc điểm đo vẽ bản đồ địa hình đáy biển ven bò' tỷ lệ lónn

Để đo vẽ bản đồ địa hình tỷ lệ lớn khu vực xây dựng công trình cảng biển, thường phải sử dụng phương pháp đo vẽ trực tiếp trên đất liền và vùng địa hình dưới nước. Địa hình dưới nước thường được đo vẽ theo phương pháp mặt cắt. Các mặt cắt đo vẽ được thiết kế vuông góc với đường bờ. Do đó, cần phải thiết kế tuyến đo sâu và dẫn đường cho tầu đo sâu đi theo đúng tuyến đo đã thiết kế.

Khu vực đo vẽ là địa hình ven bờ nên các yếu tố thuỷ triều và sóng biển sẽ có ảnh hưởng rất lớn đề kết quả đo vẽ địa hình đáy biển. Tại các vùng ven bờ của Việt Nam biên độ dao động của thuỷ triều thường đạt từ $0.5 \mathrm{~m} \div 4.0 \mathrm{~m}$ trong khi đó tại các vùng biển xa bờ biên độ dao động của thuỷ triều chỉ là $0.2 \div 0.3 \mathrm{~m}$ [2]. Vì vậy, việc quan trắc và tính số hiệu chỉnh do biên độ thuỷ triều gây ra vào kết quả đo sâu sẽ có ảnh hưởng trực tiếp đến vấn đề đảm bảo cho độ an toàn của các phương tiện vận tải ra vào cảng sau này. 
2.2. Nghiên cứu một số giải pháp kỹ thuật trong trong đo vẽ địa hình đáy biển ven bờ

2.2.1. Úng dụng công nghệ GPS trong đo vẽ địa hình đáy biển ven bờ

Để xác định vị trí mặt bằng điểm đo sâu khi đo vẽ bản đồ địa hình dưới nước thường sử dụng công nghệ DGPS và phương pháp đo GPS hiệu chỉnh toàn cầu (Gc-GPS) kết hợp với máy đo sâu hồi âm gắn trên tầu khảo sát. Công nghệ Gc-GPS cho phép đo đạc trên biển với một máy thu GPS gắn trực tiếp trên tầu đo, không cần trạm base trên bờ, do đó mà tầm hoạt động của máy không bị hạn chế, có thể đo cách xa bờ và độ chính xác định vị trên biển không phu thuộc vào vị trí tầu đo và có thể đạt cỡ $0.25 \div 1.0 \mathrm{~m}$ [3]

Về bản chất phương pháp đo Gc-GPS cũng tương tự như phương pháp định vị vi phân DGPS. Tuy nhiên phương pháp tính số hiệu chỉnh vào kết quả đo GPS tại trạm động được thực hiện trên phạm vi toàn cầu với một mạng lưới các điểm tham chiếu cơ sở đã được xác định trên toàn thế giới [3]. Máy thu C-Nav GPS được chế tạo theo công nghệ Gc-GPS có cấu tạo như hình 1.

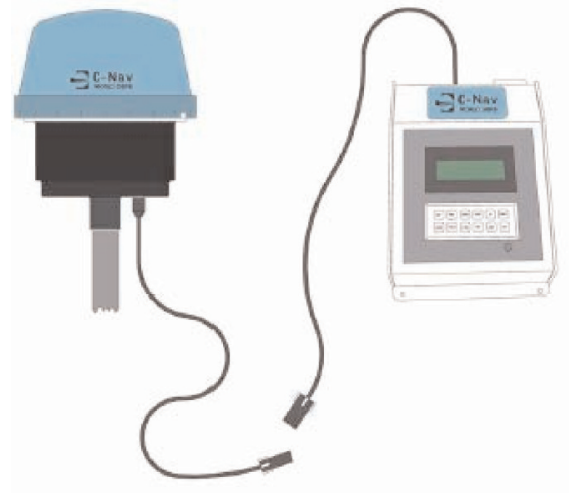

Hình 1

a. Lắp đặt kết nối máy thu GPS và máy đo sâu hồi âm trên tàu đo sâu.

Để tiến hành đo đạc địa hình đáy biển cần phải lắp đặt kết nối thiết bị máy thu GPS và máy đo sâu hồi âm trên tàu khảo sát. Tọa độ đo được là tâm anten của máy thu GPS, độ sâu được đo từ điểm đầu của cần phát biến máy đo sâu hồi âm. Yêu cầu tâm anten của máy thu GPS phải đặt trùng với tâm cần phát biến như hình 2 . Trong trường hợp do điều kiện lắp đặt trùng tâm không thể thực hiện được, khi đó có thể đặt anten của máy thu GPS ở các vị trí khác nhau trên tàu đo sâu và cần phải tính số hiệu chỉnh để tâm anten máy thu trùng với vị trí cần phát biến. Trên hình 2 giả thiết $A$ là vị trí anten thu GPS và $C$ là vị trí của cần phát biến máy đo sâu hồi âm. Khi đó cần tính chuyển toạ độ điểm đo sâu từ $\mathrm{A}$ về $\mathrm{C}$ theo công thức:

$$
\begin{gathered}
X_{C}=X_{A}+\Delta_{X} \\
Y_{C}=Y_{A}+\Delta_{Y} \\
\Delta_{X}=S_{A C} \cos \alpha_{A C} \\
\Delta_{Y}=S_{A C} \sin \alpha_{A C} \\
\alpha_{A C}=\alpha_{T}-B A C
\end{gathered}
$$

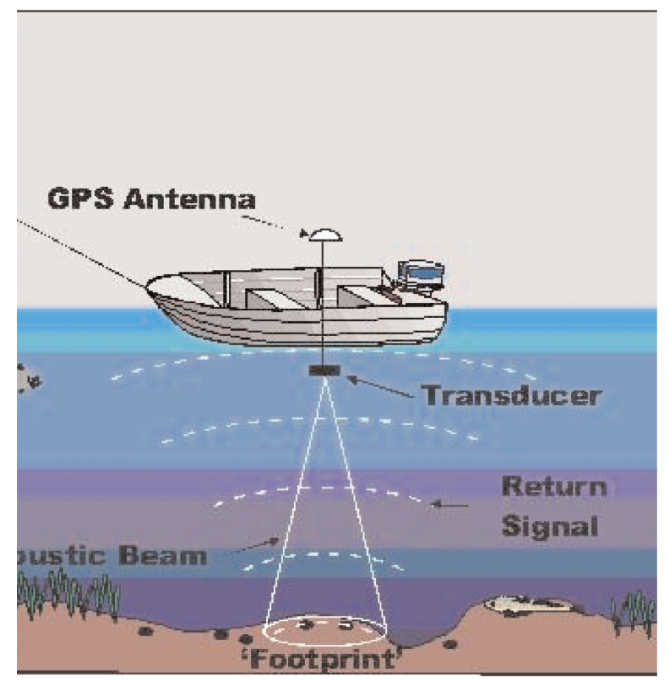

Hìn 2 


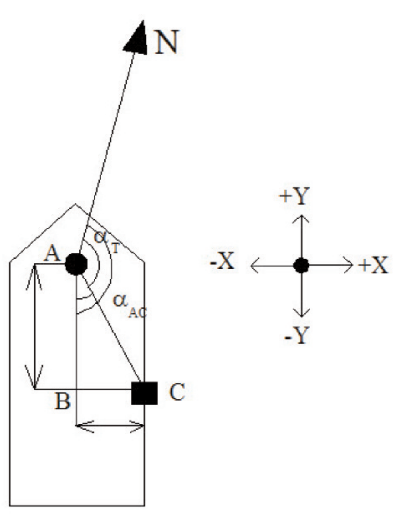

Hinh 3

b. Sử dụng công nghệ GPS để dẫn đường cho tàu đo nhằm đảm bảo đo sâu đúng tuyến đo đã thiết kế: Để bắt đầu một chuyến đo đạc trên biển, phải dẫn tàu tới điểm xuất phát của tuyến đo. Muốn vậy, đầu tiên cần phải thiết kế các tuyến đo sâu trên biển dựa vào tỷ lệ bản đồ và yêu cầu độ chính xác đo vẽ địa hình đáy biển như hình 4. Dựa vào tọa độ vị trí tàu tại bến đỗ và tọa độ đầu của một tuyến đo xác định "đường dẫn" tàu đo sâu đến vùng đo. Cài đặt các thông tin này vào phần mềm chuyên dụng đo sâu (C-Nav, Hydro...) để đưa tàu đến vùng cần khảo sát. Máy thu $\mathrm{C}-\mathrm{Nav}$ và phần mềm máy tính C-View Nav cho phép dẫn đường cho tàu chạy đúng đến khu vực cần đo và điều khiển tàu đo chạy đúng các tuyến đo đã thiết kế trên biển theo nguyên tắc dẫn đường cho tầu [4].

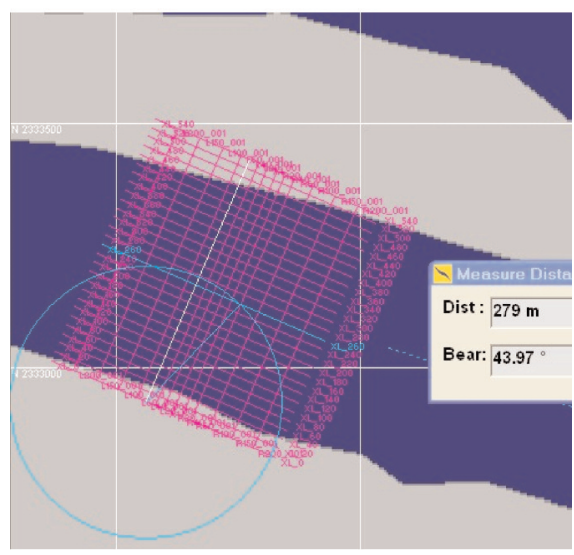

Hinh 4 c. Ứng dụng công nghệ GPS động kết hợp với máy đo sâu hồi âm trong đo vẽ bản đồ địa hình vùng đặc biệt khó khăn ven sông, ven biển.

Đặc điểm của vùng xây dựng cảng biển thường là vùng ngập nước ven biển, có hệ thực vật đa dạng phong phú và có độ sâu không lớn. Tại những vùng ngập nước này công tác đi lại và thông hướng gặp rất nhiều khó khăn và trong nhiều trường hợp không thể sử dụng các tầu đo sâu có gắn hệ thống máy GPS và máy đo sâu hồi âm để tiến hành đo vẽ vùng tiếp giáp giữa nước và bờ. Trong trường hợp này có thể sử dụng máy đo sâu cầm tay Hondex-PS7 (hình 5) kết hợp với phương pháp đo GPS động (RTK) hoăc (PPK) trên máy thu GPS một tần số hoặc hai tần số để đo vẽ địa hình vùng bán ngập nước khi khảo sát các công trình cảng biển.

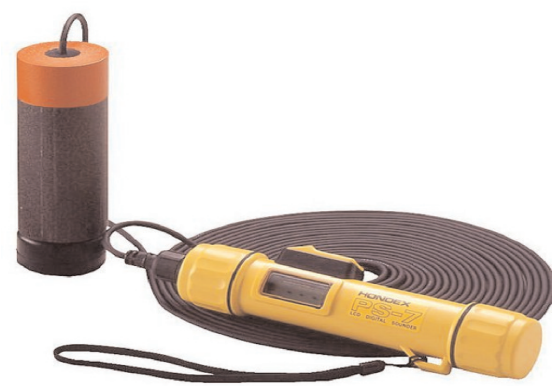

Hinh 5

Bằng công nghệ đo GPS động với 1 trạm base (hoặc hai trạm base) có thể xác định toạ độ của các điểm đo chi tiết trong bán kính $10 \mathrm{~km}$ với độ chính xác rất cao, không cần phải tăng dày lưới khống chế trạm đo trên bờ, không yêu cầu phải thông hướng ngắm và có thể đo đạc trong mọi điều kiện thời tiết. Máy đo sâu Hondex-PS7có thể đo được độ sâu $\mathrm{H}=0.6$ - $80 \mathrm{~m}$ với độ chính xác đo sâu $\mathrm{m}_{\mathrm{h}}=0.1 \mathrm{~m}$. Với sự kết hợp giữa công nghệ đo GPS động với đo sâu cầm tay hoặc 
thiết bị đo sâu thủ công (sào đo sâu hoặc dọi đo sâu) có thể tiến hành đo vẽ bản đồ địa hình vùng bán ngập nước.

2.2.2. Xác định số hiệu chỉnh do thủy triều vào kết quả đo sâu

Khi khảo sát thiết kế và và thi công xây dựng các công trình cảng biển, độ sâu của cảng và các tuyến luồng vào cảng có ảnh hưởng trực tiếp đến độ an toàn của các loại tàu thuyền ra vào cảng. Các loại bản đồ địa hình ven biển độ sâu thường được tính theo mức " 0 " hải đồ (mức nước biển trung bình thấp nhất trong vòng 100 năm), trong khi đó kết quả đo sâu trên biển là độ sâu tức thời (độ sâu tính từ mặt biển tại thời điểm đo). Tại các vùng ven bờ, biên độ dao động của thuỷ triều có ảnh hưởng rất lớn đến kết quả đo sâu. Ở nước ta biên độ dao động của mặt nước biển tức thời so với mực "0" hải đồ có thể đạt từ $0.5 \div 4 \mathrm{~m}$ [4] và đây là một yếu tố có ảnh hưởng trực tiếp đến giá trị độ sâu của điểm đo sâu trên biển.

Để xác định được độ sâu chính xác của bản đồ địa hình dưới nước ven biển, khi tiến hành khảo sát các công trình cảng biển cần phải tiến hành quan trắc thủy triều và tính số hiệu chỉnh do biên độ dao động của thủy triều để hiệu chỉnh vào kết quả đo sâu trên biển.

Số hiệu chỉnh do thuỷ triều được xác định từ các số liệu quan trắc tại các trạm nghiệm triều được bố trí tại các vùng khảo sát. Số liệu đo thuỷ triều được ghi lại theo phương pháp đo trực tiếp hoặc tự ghi bằng máy triều ký [4]. Dựa vào kết quả quan trắc mực nước tại các trạm sẽ tính được số hiệu chỉnh do biên độ dao động của thủy triều gây ra vào kết quả đo sâu.

a. Trong trường hợp các điểm đo sâu được biểu diễn theo hệ độ cao lục địa

Khi đó cần phải hiệu chỉnh độ sâu đo được về hệ đô cao lục địa:

$$
\mathrm{H}_{\mathrm{i}}=\mathrm{H}_{\text {đo }}-\mathrm{H}_{\mathrm{o}}
$$

trong đó: $\mathrm{H}_{\text {đo }}$ là độ sâu đo được bằng máy đo sâu hồi âm;

$$
\mathrm{H}_{\mathrm{o}}=\mathrm{H}_{\mathrm{tc}}-\mathrm{H}_{\mathrm{o}(\mathrm{tc})}
$$

$\mathrm{H}_{\mathrm{tc}}$ là số đọc trên thước đo mực nước;

$\mathrm{H}_{\mathrm{o}(\mathrm{tc})}$ là độ cao của số "0" trên thước đo mực nước theo hệ độ cao lục địa.

b. Trường hợp sử dụng mặt "0" hải đồ: Độ sâu đo được so với mặt nước biển tức thời cần tính chuyển về mặt " 0 " hải đồ. Trong trường hợp này cần xác định độ chênh giữa số "0" thước đo mực nước và mặt "0" hải đồ $\mathrm{d}$ tại cùng đặt trạm quan trắc mực nước biển (hình 6). Khi đó độ sâu của điểm chi tiết được tính theo công thức:

$$
\mathrm{H}_{\mathrm{i}}=\mathrm{H}_{\text {đo }}-\mathrm{H}_{\mathrm{tc}} \pm \mathrm{d}
$$

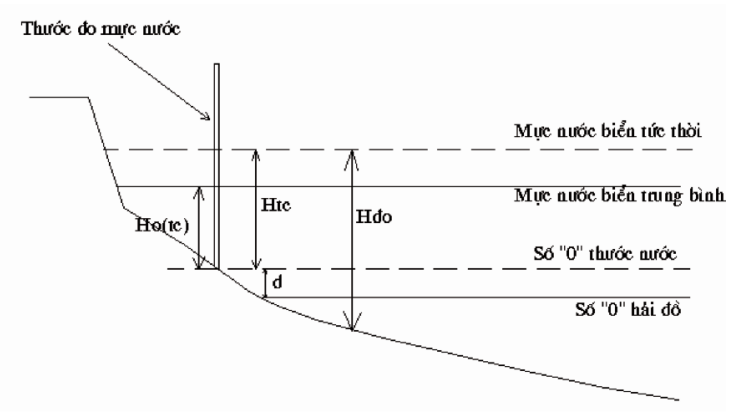

Hinh 6

Giá trị d chỉ có thể xác định được tại các tram quan trắc mực nước có thời gian quan trắc liên tục kéo dài trong vòng $18 \div 61$ năm. Các trạm quan trắc mực nước cố định đặt tại một số vị trí, hải cảng cố định (Ở Việt Nam là các trạm hòn Dấu, hòn Ngư v.v...). Vì vậy, để có được số chênh giữa số " 0 " của thước đo mực nước và mặt "0" hải đồ tại vùng đặt trạm quan trắc mực nước có thể sử dụng phương pháp "tương thích" để nội suy [2].

c. Trường hợp không có số liệu đo nghiệm triều: có thể sử dụng "nguyên lý đo vẽ bản đồ địa hình dưới nước theo cách không có nghiệm triều". Sơ đồ nguyên lý của phương pháp đo vẽ này được trình bày 
như hình 7. Độ cao của một điểm đo vẽ dưới nước $\mathrm{H}_{\mathrm{i}}$ được tính theo công thức:

$$
\begin{gathered}
\mathrm{H}_{\mathrm{i}}=\mathrm{h}_{\mathrm{k} 0}-\mathrm{h}_{\mathrm{P}} \\
h_{k 0}=h_{r}+h_{r 0}-h_{k}-\left(H_{g}^{r}-H_{g}^{k}\right)
\end{gathered}
$$

trong đó:

$h_{r}$ và $h_{k}$ là độ cao anten tại trạm $r$ và $k$

$\mathrm{h}_{\mathrm{ro}}$ là độ cao của điểm $\mathrm{r}$ (trên bờ).

$H_{g}^{r}, H_{g}^{k}$ là độ cao trắc địa của điểm $\mathrm{r}$ và $\mathrm{k}$

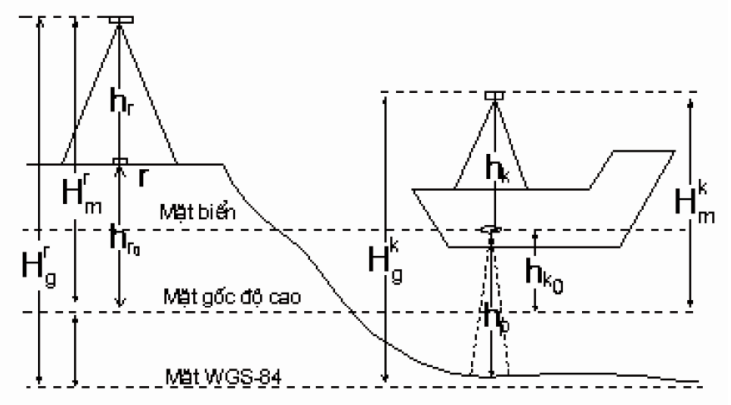

Hinh 7

Khi sử dụng nguyên lý đo vẽ này cần lưu ý rằng: khoảng cách giữa trạm tĩnh và trạm động không nên vượt quá $20 \mathrm{~km}$ và cần phải tính đến ảnh hưởng do dao động của tầu đo gây ra [1].

\section{3. Đo đạc và tính toán thực nghiệm}

Để đánh giá khả năng ứng dụng của công nghệ GPS trong đo vẽ bản đồ địa hình vùng ven bờ bán ngập nước, chúng tôi đã tổ chức đo thực nghiệm: đo vẽ địa hình dưới nước bằng công nghệ GPS động (PPK) sử dụng máy thu GPS 1 tần số Trimble -R3, máy đo sâu cầm tay Hondex - PS7 và xuồng máy để đo vẽ tại vùng bến Bạc (sông Hồng). Sơ đồ đo GPS động được bố trí với hai trạm base được đặt tại hai điểm toạ độ quốc gia (104548 và TL12). Toạ độ các điểm đo sâu được xác định theo chế độ đo Continuous và đo kiểm tra bằng một máy toàn đạc điện tử đặt trên bờ đo đến gương gắn kèm anten của máy thu GPS (hình 8). Tính giá trị chênh lệch toạ độ giữa hai phương pháp đo theo công thức

$$
\begin{gathered}
\Delta_{\mathrm{Xi}_{\mathrm{i}}}=\left(\mathrm{X}_{\mathrm{GPS}}\right)_{\mathrm{i}}-\left(\mathrm{X}_{\mathrm{T} \boxminus \oplus \mathrm{T}}\right)_{\mathrm{i}} \\
\Delta_{\mathrm{Yi}}=\left(\mathrm{Y}_{\mathrm{GPS}}\right)_{\mathrm{i}}-\left(\mathrm{Y}_{\mathrm{T} \boxminus \oplus \mathrm{T}}\right)_{\mathrm{i}} \\
m_{X}=\sqrt{\frac{\left.\Delta_{X} \Delta_{X}\right]}{2 n} ; \quad m_{y}=\sqrt{\frac{\left.\Delta_{Y} \Delta_{Y}\right]}{2 n}}} \\
m_{P}=\sqrt{m_{X}^{2}+m_{Y}^{2}}
\end{gathered}
$$

trong đó:

$\left(\mathrm{X}_{\mathrm{GPS}}\right)_{\mathrm{i}},\left(\mathrm{Y}_{\mathrm{GPS}}\right)_{\mathrm{i}}$ là toạ độ của điểm thứ $\mathrm{i}$ đo bằng GPS

$\left(\mathrm{X}_{\mathrm{TÐ \oplus T}}\right)_{i},\left(\mathrm{Y}_{\mathrm{TÐ \oplus T}}\right)_{\mathrm{i}}$ là toạ độ của điểm thứ $\mathrm{i}$ đo bằng máy toàn đạc điện tử. Kết quả đo thực nghiệm trên 55 điểm đo cho kết quả $\mathrm{m}_{\mathrm{p}}=0.160 \mathrm{~m}$. So sánh với yêu cầu độ chính xác đo vẽ bản đồ địa hình đáy biển ven bờ được dùng khi khảo sát thiết kế và thi công xây dựng các công trình cảng biển [4] cho thấy: hoàn toàn có thể sử dụng công nghệ đo GPS động và máy đo sâu hồi âm cầm tay để đo vẽ bản đồ địa hình vùng bán ngập nước ven bờ.

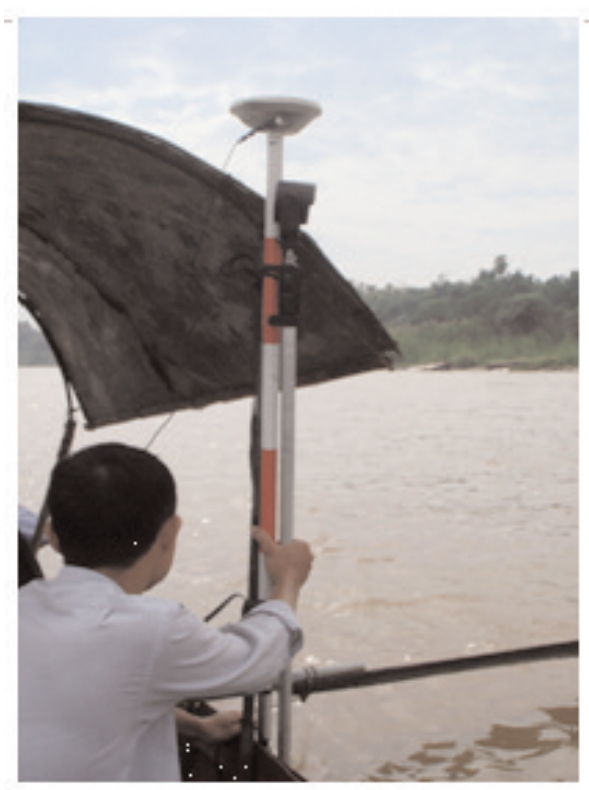

Hinh 8 


\section{Kết luận}

Từ những kết quả nghiên cứu về lý thuyết và tính toán thực nghiệm chúng tôi rút ra một số kết luận sau đây:

- Khi đo vẽ thành lập bản đồ địa hình phục vụ khảo sát thiết kế các công trình cảng biển cần phải ứng dụng một số giải pháp công nghệ chuyên dụng nhằm đảm bảo độ chính xác và nâng cao hiệu quả công tác thành lập bản đồ địa hình đáy biển ven bờ tỷ lệ lớn.

- Do địa hình xây dựng các công trình cảng biển thường ở ven bờ nên để đảm bảo độ an toàn cho các phương tiên vận tải ra vào cảng sau này cần phải đo đạc để tính số hiệu chỉnh do biên độ dao động của thuỷ triều vào kết quả đo sâu trên biển. $O$

\section{TÀl LIẸU THAM KHẢO}

[1]. Phan Văn Hiến, Nguyễn Duy Đô (2013), Giáo trình "Cơ sở trắc địa công trình", NXB Khoa học và Kỹ thuật, Hà Nội.

[2]. Phạm Hoàng Lân (1998), Cơ sở Trắc địa biển, Bài giảng cho học viên cao học Trắc địa, Đại học Mỏ - Địa chất Hà Nội.

[3]. Trần Viết Tuấn, Nguyễn Văn Hiệp (2009), "Nghiên cứu khả năng ứng dụng công nghệ GPS hiệu chỉnh toàn cầu (GcGPS) trong trắc địa công trình biển ở Việt Nam", Tạp chí KHKT Mỏ - Địa chất (số 27), Đại học Mỏ - Địa chất, Hà Nội.

[4]. Trần Viết Tuấn - Phạm Doãn Mậu (2011), "Giáo trình trắc địa biển", NXB Khoa học và Kỹ thuật, Hà Nội.O

\section{Summary}

ON THE RESEACH OF SOME TECHNICAL SOLUTIONS ESTABLISHES A SEASHORE SURFACE TOPOGRAPHY TO SURVEY AND DESIGN SEAPORTS IN VIETNAM.

\section{Dr. Tran Viet Tuan}

\section{Hanoi University of Mining and Geology}

The content of this paper shows some results of research into technical solutions which are appliedon surveying the seashore topography when surveying and designing seaports in Vietnam. In addition, this also presents some consequences of measurement and experimental calculation on the seabed. $O$

\section{Ngày nhận bài 15/3/2013.}

